\title{
Fiscal and investment indicators for evaluating professional sports facilities
}

\author{
Mikhail Gordienko*, Ksenia Ekimova, Nadezhda Glubokova, and Elena Shuvalova \\ Plekhanov Russian University of Economics, Stremyanny Lane, 36, 117997 Moscow, Russia
}

\begin{abstract}
The article is devoted to the formation of a methodology for assessing the investment and fiscal attractiveness of professional sports facilities, for which there are many similar techniques, but no single universal one. The authors made an attempt to form such a methodology, based on the ecosystem approach, within which the attractiveness of a particular object is assessed in aggregate and taking into account the interrelationships of the object and the macroeconomic environment (state, territorial and sectoral regulation), as well as the microeconomic environment (the financial position of the organization and the characteristics of the object itself). The article gives examples of indicators, their variants of values and estimated values and presents a general algorithm for applying the technique and basic formulas for calculations.
\end{abstract}

\section{Introduction}

Today there are many different approaches to assessing the investment attractiveness of organizations. Various aspects of the definition of the term "investment attractiveness" are presented by D.A. Endovitsky, N.A. Baturin, V.A. Babushkina [1], E.I. Krylova, M.N. Kreinina [2], i.a. Issues of investment attractiveness and fiscal risks of professional sports facilities are considered by Gianluigi De Mare [3], S. Janaka Biyanwila [4], Hasnul Faizal Hushin Amri [5], A.L. Balduck [6], S.J. Biyanwila [7], i.a. Each approach has its own advantages and disadvantages, while there is no universal one. Thus, this study attempts to form a methodology for assessing the attractiveness of sports facilities, taking into account investment and fiscal evaluation criteria.

Investment attractiveness as a scientific category involves taking into account some nuances. First, despite the fact that investment attractiveness is an objective concept, its assessment by a potential investor is always subjective, since it is determined by his specific goals, which may be different for each investor. In this regard, it can be argued that, depending on the purpose of the investor, his assessment of the investment attractiveness of the selected object will always be unique. Secondly, the attractiveness for the investor is characterized not only by the current state of affairs at the facility, but also by future opportunities, therefore, objective research involves focusing not only on the results already achieved, but also on predicting the prospects for its financial condition.

\footnotetext{
*Corresponding author: gordienkomikhail@yandex.ru
} 
It should be noted that each sports facility is characterized both by its own level of investment attractiveness and fiscal risks (internal factors), and depends on environmental factors. Therefore, it is important to determine the attractiveness at all levels of the environment, which together form the ecosystem, in order to compile a more holistic picture of investment potentials and fiscal risks of the assessed object. As a result, along with an analysis of the attractiveness and risks of an organization, we also propose to analyze the state of the country, region, industry and a specific organization to which the object of assessment belongs. Such an analysis will allow a potential investor to identify objects with great development potential, to more fully analyze the existing risks and prospects for making a profit. Each of the abovementioned levels has its own number of analytical indicators, due to which the most effective and comprehensive assessment is achieved. The significance of these valuation levels is different for different types of investors.

In the next section of the article, we will present the methodology of the author's approach to assessing the attractiveness of large-scale sports facilities and organizations. It should be noted that certain aspects of the methodology in each specific case need to be decomposed, refined and adjusted for the parameters of a specific sports facility. The technique requires constant improvement.

\section{Materials and Methods}

In practice, the analysis of investment attractiveness is often reduced to assessing its financial condition, which allows to analyze only the current position of the organization, but does not give the most complete picture of the prospects. In this relation, potential investor should pay attention to organizational and management structure, the level of management qualifications; the degree of uniqueness of the business concept, strategy for its development; potential for earning income from invested funds; the degree of financial transparency and openness; the level of competition in the market and the level of competitiveness; the degree of riskiness of investments; image, and other factors.

To make a decision, an investor needs a more detailed analysis of the enterprise and its attractiveness, taking into account not only quantitative but also qualitative indicators. A complex ecosystem, taking into account the interconnection of all spheres and links of the financial system, as well as factors of the internal and external environment of the object, has the following undoubted advantages:

- the object is assessed, taking into account the goals of different types of investors;

- an opportunity is created to assess organizations of different size and organizational and legal form due to the use of internal and external information about the object in the analysis;

- an approach is being universalized, which becomes possible to apply both to business owners and potential investors;

- a variety of factors are used in the assessment, which reduces risks;

- the qualitative characteristics of the enterprise and its activities are taken into account;

- a combination of several approaches allows you to compensate for the negative aspects and enhance the merits as much as possible.

Evaluation of the investment attractiveness of an individual object or organization of the professional sports industry should take into account both quantitative and qualitative characteristics, which will take into account the interests of the entire spectrum of potential users of this information. However, the potential availability of the required information must also be considered. While it is easy to obtain information about the financial 
performance of an enterprise, data on the qualitative characteristics of a company's activities are usually difficult to access and extremely subjective. Therefore, it is recommended to use only those qualitative indicators, the characteristics of which will not be difficult for the investor to verify.

Within the framework of the methodology, we consider it necessary to interpret the investment attractiveness as a relative indicator comparable to certain standard values. As a rule, the value of the weighting factors is determined by an expert judgment by the investor himself. However, in the proposed methodology, various options for calculating the integral indicator for each type of investors are possible, since the level of significance of individual indicators for them is often different. Thus, in the methodology, the assessment of the investment attractiveness of any object of professional sports will consist of five blocks and their characteristic estimated indicators (see Figure 1).

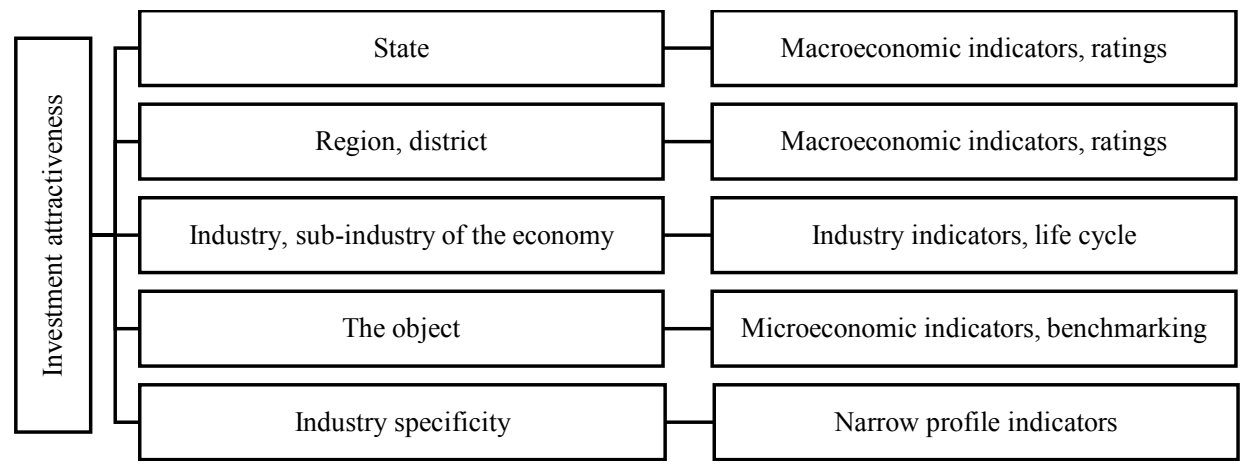

Fig. 1. The main blocks and the corresponding characteristics of the investment attractiveness of any object of professional sports.

Each indicator should be assessed by a set of factors, its components, the state of which is quantitatively determined using a point estimate, the variation of which will be in the range from 0 to 3 . Thus firstly one need to consistently consider what factors characterize the investment attractiveness of the state, region, industry and sub-industry, as well as a specific object. This approach allows a comprehensive ecosystem-based consideration of the attractiveness of an enterprise at the level of the state, region, industry, organization or a specific investment object.

\section{Results and Discussion}

Since at present stage of development there is no standard international rating that most fully characterizes all aspects of the investment attractiveness of a state, this indicator will be analyzed using a set of ratings, as well as on the basis of an assessment of investment activity in the country. Table 1 shows as an example 1 indicator "Place in the Doing Business rating" with a breakdown by states and intervals of values.

Table 1. Indicators for assessing the investment attractiveness of the country

\begin{tabular}{|c|l|c|}
\hline Indicators & \multicolumn{1}{|c|}{ Status and value ranges } & $\begin{array}{c}\text { Rating } \\
\text { scale }\end{array}$ \\
\hline & The country is in the top $30 \%$ of places in the ranking & 3 \\
Ranking place & The country is in the second $30 \%$ of places in the ranking & 2 \\
Doing Business & The country is in the third $30 \%$ of places in the rating & 1 \\
& The country is in the last $10 \%$ of places in the ranking & 0 \\
\hline
\end{tabular}

Source: compiled by the authors. 
Since the volume of the publication is limited, let us list the rest of the indicators introduced by analogy and also estimated from 0 to 3 points: place in the Standard \& Poors rating; place in the ranking of the global competitiveness index; place in the ranking of the index of weakness of states; dynamics of investment activity; the level of fiscal burden and the quality of tax administration, etc.

It is proposed to evaluate the attractiveness of the region in which the enterprise is located based on its place in the rating of investment attractiveness of the regions of the state. To do this, it is worth resorting to data from state statistics bodies or data from rating agencies. For Russia, the data of the rating agency Expert RA are representative, as one of the most complete and diverse studies, which is presented in Table 2.

Table 2. Indicators for assessing the investment attractiveness of the region

\begin{tabular}{|c|l|c|}
\hline Indicators & \multicolumn{1}{|c|}{ Status and value ranges } & $\begin{array}{c}\text { Rating } \\
\text { scale }\end{array}$ \\
\hline Place in the rating of & Region belongs to category A & 3 \\
investment & Region belongs to category B & 2 \\
attractiveness of the & Region belongs to category C & 1 \\
regions Expert RA & Region belongs to category D & 0 \\
\hline
\end{tabular}

Source: compiled by the authors.

It is proposed to assess the attractiveness of the industry on the basis of an analysis of the qualitative and quantitative indicators of the organization of this industry, an assessment of the direction of investment flows in it. Each indicator, as in Tables 1 and 2, is expertly assigned intervals of values. Let's list the main indicators: the number of unprofitable enterprises in the industry; number of innovations; direction of investment flows in the industry; the degree of wear of the fixed assets of the industry; quick and absolute liquidity, financial dependence, financial leverage ratios; profitability of sales, assets; term of work in the market; market share; the degree of competition; the sensitivity of products to price volatility in the market and fluctuations in demand; business reputation; level of innovative activity; the level of tax burden on the industry.

To assess the investment attractiveness of an enterprise, an analysis of both quantitative indicators characterizing the financial condition of the enterprise and qualitative indicators describing the business reputation of the company, its position in the market, and the economic potential of the activity will be required. The financial position of an enterprise is proposed to be assessed by the indicators of 4 groups of coefficients: profitability, financial stability, liquidity and business activity. It is recommended to take no more than 2 indicators from each group, since the coefficients within the group have a high degree of correlation [7].

In addition to the presented macro- and microeconomic criteria, we consider it necessary to apply indicators in the methodology that take into account the industryspecific nature of organizations or specific investment projects implemented in the field of professional sports. Let us turn to the normative legal acts in the field of professional sports in order to find the most objective approaches to the classification of specialized objects. The most suitable, in our opinion, is the classifier approved by the order of the profile regulator $[\ldots]$, which presents the most complete list of sports facilities and their detailed characteristics. The classifier takes into account the functional features and infrastructural parameters of a particular object, in accordance with which the object is assigned a certain point. We will give an example of classification for the "stadium" object intended for playing European football; we will not use other non-representative classification parameters from the order in this case. The rating scale remains the same (see table 3 below) $[8,9]$. 
Table 3. Indicators for assessing the industry specificity of an organization or project

\begin{tabular}{|c|l|c|}
\hline Indicators & \multicolumn{1}{|c|}{ Status and value ranges } & $\begin{array}{c}\text { Rating } \\
\text { scale }\end{array}$ \\
\hline \multirow{5}{*}{ Stadium } & Indoor specialized with natural turf for football & 3 \\
& Indoor specialized with artificial turf for football & 3 \\
& Outdoor versatile natural turf for football and artificial turf for & 3 \\
& athletics & 2 \\
& Outdoor specialized with natural turf for football & 2 \\
& Outdoor versatile with natural turf for football and athletics & 1 \\
& Outdoor specialized with artificial turf for football & 1 \\
\cline { 2 - 3 } & Outdoor all-purpose artificial turf for football and athletics & \\
\hline
\end{tabular}

Source: compiled by the authors.

Thus, the first stage of the methodology is to determine the values of the scoring factors of factors characterizing the investment attractiveness of a country, region, industry, enterprise, object - IR $, I_{R}, I_{O}, I R_{P}, I_{S O}$, respectively. These indices represent an integral assessment of the lower-order attractiveness factors that are included in them, taking into account their weight for different types of investors.

The attractiveness of a country is estimated as a percentage using formula 1:

$$
\mathrm{IR}_{\mathrm{S}}=\frac{\sum_{i=1}^{n} F_{i},}{\sum_{i=1}^{n} F_{i \max }} \times 100 \%
$$

where $F_{i}-$ is the score of the $i$-th factor of the country's investment attractiveness; $F_{i \text { max }}-$ is the maximum possible score for the $\mathrm{i}$-th factor of the country's investment attractiveness.

The attractiveness of a region is estimated as a percentage using formula 2 :

$$
\mathrm{IR}_{\mathrm{R}}=\frac{\mathrm{IR}}{\mathrm{IR}_{\max }} \times 100 \%
$$

where IR - баліs a point assessment of the region's place in the rating of investment attractiveness of the most authoritative rating agency; $\mathrm{IR}_{\max }-$ is the maximum point estimate of the region's place in the investment attractiveness rating of an authoritative rating agency.

The attractiveness of the industry is estimated as a percentage using formula 3:

$$
\mathrm{IR}_{\mathrm{o}}=\frac{\sum_{j=1}^{n} F_{j},}{\sum_{j=1}^{n} F_{j \max }} \times 100 \%
$$

где $F_{j}$ - is the point estimate of the $j$-th factor of the investment attractiveness of the industry; $F_{j \max }-$ is the maximum possible score for the $i$-th factor of the industry's investment attractiveness.

To measure the investment attractiveness of an enterprise, two groups of indicators are used: financial and non-financial.

The attractiveness of the company is estimated as a percentage using the formula 4 :

$$
\mathrm{IR}_{\mathrm{P}}=\frac{\sum_{k=1}^{n} F_{k}}{\sum_{k=1}^{n} F_{k \max }} \times 100 \%
$$

where $F_{k}$ - is the point estimate of the kth factor of the investment attractiveness of the enterprise; $F_{k \max }-$ is the maximum possible score for the $k$-th factor of the investment attractiveness of the enterprise.

Investment attractiveness also takes into account the industry specificity of the organization or the characteristics of a specific project in the field of professional sports, which is assessed as a percentage using formula 5 : 


$$
\mathrm{IR}_{\mathrm{SO}}=\frac{\sum_{j=1}^{n} F_{\mathrm{p}}}{\sum_{j=1}^{n} F_{\mathrm{p}} \max } \times 100 \%
$$

where $F_{p}$ - is the score of the $j$-th factor of the industry specificity of an organization or a specific project; $F_{p \max }$ - the maximum possible score of the i-th factor, the industry specificity of an organization or a specific project.

The integral indicator of the methodology is the result of summing the values of investment attractiveness factors, which are obtained as a result of multiplying the assessment of these factors on a three-point scale by their weight in the overall assessment of investment attractiveness, which is assigned separately by each investor in accordance with his interests. The Integral Indicator (II) is calculated using the formula 6:

$$
I I=I R_{S} \times V_{S}+I R_{R} \times V_{I R r}+I R_{\mathrm{o}} \times V_{I R o}+I R_{P} \times V_{I R p}+I \mathrm{I}_{\mathrm{SO},} \times V_{I R s o}
$$

где $I R_{S}, I_{R}, I R_{0}, I R_{P}, I_{S O}$ - is an assessment of indicators of the investment attractiveness of a country, region, industry and the enterprise itself, respectively, in percentage terms; $\mathrm{V}_{\text {IRs }}, \mathrm{V}_{\text {IRr }}, \mathrm{V}_{\text {IRo }}, \mathrm{V}_{\text {IRp }}, \mathrm{V}_{\text {IRso }}$ - the weight of the corresponding factors of attractiveness in the integral assessment, respectively.

The sequence of calculating the integral indicator of attractiveness:

1) each single indicator characterizing the factors of the attractiveness of a country, region, industry and enterprise (factors of the third level) is assessed on a scale from 0 to 3 points (a more complex scale is also possible);

2) by summing the scores of the attractiveness factors, the values of the integral indicators of the attractiveness of a country, region, industry, enterprise and a specific object are calculated - IRS, IR $, I_{R}, I R_{P}, I_{S O}$ - respectively. Then these estimates are presented in a comparable form, in percentage format;

3) the final integral indicator of attractiveness is calculated by summing the products of integral indicators of the attractiveness of a country, region, industry, enterprise and object, taking into account their weight for a particular investor (in this case, the sum of the weights should always be equal to 1 );

4) the obtained value is compared with the maximum possible ideal (equal to $100 \%$ ) and on the basis of this, a conclusion is made about the state of investment attractiveness and fiscal risks of the assessed object as a whole.

\section{Conclusions}

The use of the above-described methodology and the integral ecosystem indicator included in it in the analysis of the attractiveness of the object of analysis in the sphere of professional sports has the following advantages:

- bring together qualitative and quantitative indicators in one assessment;

- takes into account the significance of various factors, including industry-specific, for different types of investors in the final assessment (takes into account the typology of investors);

- makes it possible to compare the level of investment attractiveness and fiscal parameters of enterprises to select the best investment object;

- allows you to adjust the resulting factors to increase the attractiveness of the enterprise in order to further expand and develop. 


\section{Acknowledgements}

The article was prepared within the framework of the research work "Development of scientifically grounded proposals for increasing the investment attractiveness of professional sports in the Russian Federation", with the support of the Federal State Budgetary Educational Institution of Higher Education « Plekhanov Russian University of Economics».

\section{References}

1. D. A. Endovitsky, V. A. Babushkin, N. A. Baturina, Analysis of the investment attractiveness of the organization: scientific publication (2012)

2. S.I. Krylov, Financial analysis: textbook (2012)

3. De Mare G., Granata M.F., F. Forte, CCSA 2015, Lecture Notes in Computer Science, Springer, Cham, 9157 (2015)

4. S.J. Biyanwila, Sports and The Global South, Global Culture and Sport Series, Palgrave Macmillan, Cham (2018)

5. H.F.H. Amri, S.A. Wahab, N. Salamuddin, M.T. Harun, ICoSSEET 2016, Springer, Singapore (2019)

6. A.L. Balduck, S. Lucidarme, M. Marlier, Voluntas 26, 2023 (2015)

7. E.V. Golubtsova, A.O. Zvereva, IBIMA 2019: Education Excellence and Innovation Management through Vision 2020 (2019)

8. M.E. Kosov, R.G. Akhmadeev, V.S. Osipov, Y.K. Kharakoz, I.I. Smotritskaya, Indian Journal of Science and Technology (2016)

9. R. Akhmadeev, T. Morozova, O. Voronkova, A. Sitnov, Entrepreneurship and Sustainability Issues (2019) 